\title{
Age-related changes of malondialdehyde, body weight and organ weight in male mice
}

\author{
Dwi Nur Ahsani* and Ika Fidianingsih*
}

\begin{abstract}
\section{INTRODUCTION}

Aging is characterized by gradual impairment in all physiological functions. Increases in free radicals and changes in organ morphology occur with aging. The purpose of this study was to determine age-related changes in serum free radicals, body weight, organ weights, and relative organ weights in male mice.
\end{abstract}

\section{METHODS}

An experimental animal study was performed on 25 male mice (Mus musculus), which were randomized into 5 groups according to age at termination, i.e. 12 (group K1), 24 (K2), 32 (K3), 40 (K4) and 48 weeks (K5), respectively. Retro-orbital venous blood was taken for examination of malondialdehyde (MDA) levels. After termination, liver, heart, kidneys, testes, brain, thymus and spleen were weighed using an analytical balance. ANOVA and Kruskal Wallis tests were used to analyze the data, with $\mathrm{p}<0.05$ being considered significant.

\section{RESULTS}

Significant changes were found with age in serum MDA level $(p=0.000)$, body weight $(p=0.000)$, and weights of all organs except thymus $(p>0.05)$ (liver $\mathrm{p}=0.023$, heart $\mathrm{p}=0.000$, kidneys $\mathrm{p}=0.002$, testes $\mathrm{p}=0.000$, brain $\mathrm{p}=0.012$ and spleen $\mathrm{p}=0.006)$. Significant changes in relative weight of brain $(\mathrm{p}=0.001)$ and spleen $(\mathrm{p}=0.049)$ were also found with age.

\section{CONCLUSION}

This study demonstrated increases in serum MDA levels, body weight, and weights of the liver, heart, kidneys, testes, brain and spleen with age. Peak increases in weights of kidneys and thymus were found earlier than those in MDA levels and weights of other organs.

Keywords : Body weight, organ weight, malondialdehyde, age, male mice
*Department of Histology,

Faculty of Medicine,

Islamic University of Indonesia, Yogyakarta

\section{Correspondence:}

Dwi Nur Ahsani,MD,M.Sc

Department of Histology,

Faculty of Medicine,

Islamic University of Indonesia,

Yogyakarta

Jl. Kaliurang Km14,5 Sleman

Yogyakarta.

Phone: (+62) 85229030982.

Fax :(+62) 274898444 Ext.2007.

Email: dwinurahsani@gmail.com or

dwi.nurahsani@uii.ac.id

Date of first submission, December 15,2017

Date of final revised submission, June 22, 2018

Date of acceptance, June 25, 2018

This open access article is distributed under a Creative Commons AttributionNon Commercial-Share Alike 4.0

International License

Cite this article as: Ahsani DN, Fidianingsih I. Age-related changes of malondialdehyde, body weight and organ weight in male mice Univ Med 2018;37:115-26. doi: 10.18051/ UnivMed. 2018.v37.115-126 


\section{INTRODUCTION}

Aging is a naturally occurring process in living organisms that is marked by increases in body functions up to a given age, when it is followed by decreases in body function, resulting in a variety of medical conditions that ultimately increase an individual's susceptibility to disease. ${ }^{(1)}$ Several studies showed that persons older than 63 years have at least one chronic disease. Degenerative diseases commonly found in older persons are hypertension, visual disorders, anemia, diabetes mellitus, disorders of mobility, and diseases of the central nervous system such as dementia and stroke. ${ }^{(2-4)}$

Cellular aging is marked by increases in free radical concentrations in the body, causing damage to the structure of cellular lipids, proteins, and also DNA. In physiological conditions, increases in free radicals are inhibited by antioxidant enzymes. ${ }^{(5)}$ One study showed that aging causes decreased expression of antioxidant proteins. Western blot assays showed increased oxidative stress levels in the liver. Aging decreases the activities of superoxide dismutase, catalase and glutathione and increased lipid peroxidation and 70 kilodalton heat shock protein (Hsp70) levels in the brain and also in peripheral organs such as the liver, kidneys and heart. ${ }^{(6)}$

One of the markers of oxidative stress is malondialdehyde (MDA), which is a product of lipid peroxidation with mutagenic, cytotoxic, and carcinogenic properties, due to its inhibitory effect on antioxidant enzymes. Therefore, increased MDA concentration is frequently used as one of markers of disordered homeostasis and aging. ${ }^{(7)}$

Other studies showed that oxidative stress is associated with weight increase (obesity), which increases the risk for various degenerative disorders such as cardiovascular disease and the metabolic syndrome. ${ }^{(8,9)}$ Increased body weight also induces chronic inflammatory conditions with age, ultimately causing organ degeneration. ${ }^{(10)}$
Morphological changes of an organ are important for identifying abnormalities of the organ and evaluating the phase of a disease in a patient. The weight of an organ is important to be recognized as clinical parameter in several disciplines, e.g. for determining the toxic effects of new drugs in pharmacology and the limits of radiation exposure in radiology. ${ }^{(11,12)}$ Morphological changes in an organ cause functional disorders in older persons.

Studies associated with age-related organ weight have been frequently conducted for various purposes. Studies on the weight of internal organs in humans are commonly performed by forensic clinicians in post-mortem situations to obtain the normal weights of organs in relation to race or gender. ${ }^{(13-15)}$ In experimental animals, studies on changes in organ mass are aimed at determining the agerelated developmental pattern of an organ and also the underlying mechanism of the aging process. ${ }^{(16-19)}$ Therefore, studies on experimental animals are far more feasible to be performed by investigators as compared with studies on humans.

The patterns of changes in organ size differ between organs. A study on Wistar rats showed that the volume of the kidneys increases up to the age of 12 months and decreases afterwards. ${ }^{(18)}$ The brain experiences a rapid increase in volume at the age of less than 20 weeks and thereafter the development becomes static. ${ }^{(19)}$ In humans, there is a negative correlation between aging and the weight of the brain, kidneys, liver, and spleen. ${ }^{(14)}$ On the other hand, a positive correlation is found between aging and morphological changes of the heart. ${ }^{(15)}$ In humans, aging not only changes the morphology of the organs, but also increases body weight. ${ }^{(20)}$

An in-depth study should be carried out in connection with the accumulation of free radicals and the morphological organ changes occurring with age. There is still controversy on the relationship of aging with increased free radical levels and functional organ changes. The study 
by Luceri et al. ${ }^{(21)}$ showed that aging increases plasma reactive oxygen species (ROS) and protein carbonyl concentrations, which are clearly seen in 15-month old rats. Systemic increases in ROS concentrations also cause damage to the liver, as shown in the increased DNA oxidative markers in the liver (8-hydroxy22 -deoxyguanosine/8-OHdG) and decreased expression of the DNA repair gene apyrimidinic endonuclease-1 (APE-1). On the other hand, the study by Gomes et al. ${ }^{(22)}$ showed no relationship between increased oxidative stress and functional changes in the kidneys of aging rats. This was shown by the increases in free radicals in the kidneys (MDA in urine and $\mathrm{H}_{2} \mathrm{O}_{2}$ in the renal cortex and medulla) and in plasma MDA in 52-week old rats, but without increases in creatinine and sodium concentrations. In view of the inconclusive study results, further studies are still needed. The present study aimed to determine the changes in plasma MDA and free radical concentrations, as well as the age-related changes in body weight and organ weights in male mice.

\section{METHODS}

\section{Study design}

This study was an experimental animal study conducted from September 2016 until March 2017 at the Physiology Laboratory, Faculty of Medicine, Universitas Islam Indonesia (FK UII).

\section{Study subjects}

The mice were obtained from the Physiology Laboratory, FK UII. The mice received care at the FK UII research laboratory according to the principles of experimental animal welfare. All animals received feed and drinking water ad libitum and were kept in group cages, each containing one group of 5 mice. The experimental animals had adequate ventilation and were kept on a 12-hour light-dark cycle. All mice were offspring of one dam. A total of 10 male mice (Mus musculus) aged 8 weeks and
15 male mice aged 16 weeks were entered into this study. There were 5 groups in this study, i.e. the groups of mice terminated at ages of 12 (K1), 24 (K2), 32 (K3), 40 (K4) and 48 weeks (K5), respectively. Groups K1 and K2 comprised 8 -week old mice that were kept until the previously determined ages of termination (12 and 24 weeks, respectively), whereas groups K3, K4 and K5 comprised 16-week old mice that were kept until the previously determined ages of termination (32, 40 and 48 weeks, respectively).

\section{Sample size calculation}

The number of experimental animals used in this study was determined by means of the formula of Charan and Khantaria ${ }^{(23)}$ i.e. $E=$ total number of animals - total number of groups. $E$ is a constant within the range of 10-20. According to the calculation, the total number of animals that should be used in this study is 15-25 rats, with each group consisting of 3-5 mice. In this study it was decided to use 5 animals in each group, so that the total number of experimental animals used in this study was 25.

There was no special treatment for the experimental animals. The study subjects (mice) were kept until the previously determined ages $(12,24,32,40$, and 48 weeks). As part of their care, the mice received feed and drinking water ad libitum, were kept in group cages and were subjected to light-dark cycles. The mice used in this study were healthy purebred males without disabilities and had never been used for research. Mice with abnormal behavior (those that were apparently weak, inactive, ill, or aggressive) or those that died in the course of the study, were not included.

\section{Measurements and laboratory analysis}

On the day of termination determined previously, the mice were weighed on an animal balance to obtain data on body weight. Subsequently the mice were anesthetized by intramuscular injection of $0.2 \mathrm{ml}$ ketamine. Then 
3-ml venous blood samples were drawn from the right and left retro-orbital veins using capillary tubes after the mice were unconscious. Each blood sample was placed in an EDTA-containing Eppendorf tube. After a sufficient volume of venous blood had been obtained, the experimental animals were terminated by transcardial perfusion, using physiologic saline $(\mathrm{NaCl})$ followed by PBS $10 \%$ formol fixative. The following organs were taken and dried on filter paper, namely the brain (cerebrum and cerebellum), heart, thymus, spleen, liver, both testes and both kidneys. After drying, each organ was weighed on an analytical balance and the organ weight recorded, expressed in grams.

The blood samples obtained from each of the experimental animals were centrifuged to obtain the respective sera, which were taken with micropipettes and placed in separate Eppendorf tubes. The sera were subsequently sent to the laboratory of the Gadjah Mada University Inter-University Center (Pusat Antar Universitas Universitas Gadjah Mada, PAU FK UGM) for measurement of MDA concentrations, using the thiobarbituric acid reactive substances (TBARS) assay. To each 100 microliters of serum was added $2.45 \mathrm{ml}$ trichloro-acetic acid (TCA) and $2.45 \mathrm{ml}$ thiobarbituric acid (TBA). The mixture was heated to $100^{\circ} \mathrm{C}$ for 20 minutes, then centrifuged for 10 minutes at $8000 \mathrm{rpm}$. Absorbance of the compound formed was determined from the standard curves. The MDA concentration was expressed in nanomol/gram $(\mathrm{nmol} / \mathrm{g})$.

\section{Statistical analysis}

The analysis was performed using the SPSS $^{\circledR}$ for Windows software. The study data were displayed in a table as mean \pm standard deviation. The body weights and organ weights of the mice were expressed in grams $(\mathrm{g})$ whereas the MDA concentrations were expressed in nanomol/gram ( $\mathrm{nmol} / \mathrm{g})$. Mean relative organ weights were obtained from the ratio of mean organ weights to mean body weight of the mice in the same group.
The data analysis started with the ShapiroWilk test of normality of data and Levene's test of homogeneity of data. On normally distributed and homogeneous data, one-way ANOVA was used as test of significance, whereas on nonnormally distributed and/or non-homogeneous data the Kruskal Wallis test was used.

One-way ANOVA was performed to determine the significance of the differences between mean body weight, mean weights of liver, heart, kidneys, and testes, and mean MDA concentrations in each group. One-way ANOVA was also used to determine the significance of mean organ weights of brain, liver, heart, kidneys, testes, and spleen relative to mean body weights of the mice. The nonparametric Kruskal-Wallis test was performed to determine the significance of the differences between means of the weights of the brain, thymus, spleen and mean relative weight of the thymus. The post-hoc LSD test was performed on data that were found to be statistically significant by the parametric one-way ANOVA test (body weight, organ weights of liver, heart, kidneys, and testes, MDA concentration and brain relative weight), whereas the MannWhitney test was performed on data that showed statistically significant results (weights of brain and thymus relative to body weight).

\section{Ethical clearance}

Ethical clearance for this experimental animal study was granted under no. 10/ Ka.Kom.Et/ 70/KE/XI/2016 before this study was conducted.

\section{RESULTS}

A total of 24 mice successfully completed the study up to the time points determined previously in the protocol. One mouse was removed from group $\mathrm{K} 3$ since it died before the time point determined (before 32 weeks). The body weights of the 24 mice were determined prior to necropsy. Twenty four organs, comprising the brain, liver, heart, thymus, spleen, both 
kidneys and both testes, were collected at termination. Twenty-three blood samples for MDA determination were successfully obtained from 23 mice. No blood sample was collected from one mouse in the 32-week group (K3).

The ANOVA test results showed a significant difference in mean serum MDA concentration $(p=0.000)$ and mean body weight $(p=0.000)$. Significant differences in mean organ weight were encountered for nearly all organs [liver $\mathrm{p}=0.023)$, heart $(\mathrm{p}=0.000)$, kidneys $(\mathrm{p}=0.002)$, testes $(\mathrm{p}=0.000)$, brain $(\mathrm{p}=0.012)$ and spleen $(\mathrm{p}=0.06)$, except the thymus $(\mathrm{p}>0.05)]$. Significant differences in relative mean organ weight was found for the brain $(\mathrm{p}=0.001)$ and spleen $(\mathrm{p}=0.049)$. With regard to the parameter of organ weight relative to body weight of the experimental animals, there were no significant differences in the relative organ weights of the liver, heart, kidneys, testes, and thymus ( $\mathrm{p}>0.05$, Table 1).

The post-hoc test showed significant differences in MDA concentration and body weight between group $\mathrm{K} 5$ and all other groups $(\mathrm{K} 1, \mathrm{~K} 2, \mathrm{~K} 3, \mathrm{~K} 4)$ and between $\mathrm{K} 3$ and $\mathrm{K} 4$. With regard to the parameter of body weight, a significant difference was seen between $\mathrm{K} 1$ and all other groups, and between group $\mathrm{K} 2$ and groups K3 and K4 (Table 2). In the post-hoc test, the parameter of organ weight showed a significant difference between group $\mathrm{K} 1$ and groups $\mathrm{K} 4$ and $\mathrm{K} 5$ for the liver, also between groups $\mathrm{K} 1$ and $\mathrm{K} 5$ versus all other groups and between $\mathrm{K} 2$ and $\mathrm{K} 4$ for the heart. There was a significant difference between group $\mathrm{K} 1$ and groups $\mathrm{K} 3, \mathrm{~K} 4$, and $\mathrm{K} 5$, and between $\mathrm{K} 2$ and groups $\mathrm{K} 3$ and $\mathrm{K} 5$ with regard to the parameter of the weight of the kidneys. The weight of the testes showed a significant difference between group $\mathrm{K} 5$ and groups $\mathrm{K} 1$ and $\mathrm{K} 2$, between $\mathrm{K} 1$ versus $\mathrm{K} 3$ and $\mathrm{K} 4$, and between $\mathrm{K} 2$ and $\mathrm{K} 4$ (Table 3). The weight of the brain relative to body weight showed a significant difference between group $\mathrm{K} 1$ versus all other groups and between K2 and K3 (Table 4). The relative weight of the spleen showed a significant difference between $\mathrm{K} 2$ versus $\mathrm{K} 4$ and $\mathrm{K} 5$, and between K3 versus K4 and K5 (Table 4).

\section{DISCUSSION}

This study showed that in the experimental animals aging was marked by an increase in MDA concentration in the blood. This study

Table 1. MDA concentration, body weight, organ weight, relative organ weight of mice

(Mus musculus) in various groups

\begin{tabular}{|c|c|c|c|c|c|c|}
\hline \multirow[t]{2}{*}{ Parameter } & K1 $(n=5)$ & $K 2(n=5)$ & $\begin{array}{c}\text { Group } \\
\text { K3 (n=4) }\end{array}$ & $K 4(n=5)$ & $K 5(n=5)$ & \multirow[t]{2}{*}{ p value } \\
\hline & Mean \pm SD & Mean \pm SD & Mean \pm SD & Mean \pm SD & Mean \pm SD & \\
\hline MDA $(\mathrm{mmol} / \mathrm{ml})^{\S}$ & $3.79 \pm 0.76$ & $3.854 \pm 0.46$ & $4.405 \pm 0.3$ & $3.21 \pm 0.52$ & $6.705 \pm 0.20$ & $0.000^{*}$ \\
\hline Body weight : BW $(\mathrm{g})^{\S}$ & $26.9 \pm 2.19$ & $34.7 \pm 3.36$ & $40.8 \pm 5.95$ & $40.5 \pm 3.62$ & $47.52 \pm 4.28$ & $0.000^{*}$ \\
\hline \multicolumn{7}{|l|}{ Organ weight : OW (g) } \\
\hline Liver $\S$ & $1.43 \pm 0.16$ & $1.89 \pm 0.49$ & $1.91 \pm 0.48$ & $2.19 \pm 0.3$ & $2.27 \pm 0.41$ & $0.023 *$ \\
\hline Heart $^{\S}$ & $0.12 \pm 0.02$ & $0.14 \pm 0.01$ & $0.18 \pm 0.06$ & $0.19 \pm 0.03$ & $0.23 \pm 0.01$ & $0.000 *$ \\
\hline Kidneys ${ }^{\S}$ & $0.32 \pm 0.03$ & $0.44 \pm 0.18$ & $0.68 \pm 0.06$ & $0.54 \pm 0.09$ & $0.60 \pm 0.15$ & $0.002 *$ \\
\hline Testes $\$$ & $0.17 \pm 0.03$ & $0.22 \pm 0.05$ & $0.25 \pm 006$ & $0.3 \pm 0.02$ & $0.29 \pm 0.04$ & $0.000 *$ \\
\hline Brain $\$ \S$ & $7.00 \pm 0.18$ & $6.60 \pm 0.20$ & $12.75 \pm 0.15$ & $17.4 \pm 0.20$ & $18.80 \pm 0.02$ & $0.012 *$ \\
\hline Thymus $\S$ & $10.10 \pm 0.01$ & $12.50 \pm 0.03$ & $15.13 \pm 0.12$ & $17.50 \pm 0.02$ & $7.80 \pm 0.01$ & 0.211 \\
\hline Spleen ${ }^{\S}$ & $10.20 \pm 0.08$ & $5.80 \pm 0.03$ & $8.75 \pm 0.04$ & $16.00 \pm 0.03$ & $21.00 \pm 0.09$ & $0.006^{*}$ \\
\hline \multicolumn{7}{|c|}{ Relative organ weight (OW/BW) } \\
\hline Liver $^{\S}$ & $0.053 \pm 0.006$ & $0.054 \pm 0.009$ & $0.046 \pm 0.005$ & $0.055 \pm 0.011$ & $0.047 \pm 0.007$ & 0.405 \\
\hline Heart ${ }^{\S}$ & $0.004 \pm 0.001$ & $0.004 \pm 0.001$ & $0.004 \pm 0.001$ & $0.005 \pm 0.001$ & $0.005 \pm 0.000$ & 0.611 \\
\hline Kidneys $\S$ & $0.012 \pm 0.001$ & $0.012 \pm 0.004$ & $0.017 \pm 0.001$ & $0.013 \pm 0.002$ & $0.012 \pm 0.002$ & 0.125 \\
\hline Testes $\$$ & $0.006 \pm 0.001$ & $0.006 \pm 0.001$ & $0.006 \pm 0.001$ & $0.007 \pm 0.001$ & $0.006 \pm 0.001$ & 0.188 \\
\hline Brain $^{\S}$ & $0.015 \pm 0.001$ & $0.012 \pm 0.001$ & $0.009 \pm 0.003$ & $0.011 \pm 0.001$ & $0.01 \pm 0.000$ & $0.001^{*}$ \\
\hline Thymus $\$ \S$ & $0.004 \pm 0.004$ & $0.002 \pm 0.000$ & $0.002 \pm 0.001$ & $0.004 \pm 0.001$ & $0.006 \pm 0.002$ & 0.09 \\
\hline Spleen ${ }^{\S}$ & $0.002 \pm 0.001$ & $0.001 \pm 0.001$ & $0.002 \pm 0.003$ & $0.001 \pm 0.000$ & $0.001 \pm 0.000$ & $0.049^{*}$ \\
\hline
\end{tabular}

K1 : 12 weeks, K2 : 14 weeks, K3 : 32 weeks, K4 : 40 weeks, K5 : 48 weeks ${ }^{\S}$ : Anova, ${ }^{\S}$ : Kruskal-Wallis test, *: p $<0.05$ 
Table 2. LSD post-hoc test on MDA concentration and body weight of mice (Mus musculus) in various groups

\begin{tabular}{|c|c|c|c|c|}
\hline Parameter & & & Mean difference & p value \\
\hline \multirow[t]{10}{*}{ MDA level } & K1 & $\mathrm{K} 2$ & -0.06400 & 0.845 \\
\hline & & K3 & -0.61500 & 0.089 \\
\hline & & K4 & 0.58000 & 0.089 \\
\hline & & K5 & $-2.91500^{*}$ & $0.000 *$ \\
\hline & $\mathrm{K} 2$ & $\mathrm{~K} 3$ & -0.55100 & 0.124 \\
\hline & & K4 & 0.64400 & 0.061 \\
\hline & & K5 & $-2.85100^{*}$ & $0.000^{*}$ \\
\hline & K3 & K4 & $1.19500^{*}$ & $0.003^{*}$ \\
\hline & & K5 & $-2.30000^{*}$ & $0.000^{*}$ \\
\hline & K4 & K5 & $-3.49500^{*}$ & $0.000^{*}$ \\
\hline \multirow[t]{10}{*}{ Body weight } & K1 & $\mathrm{K} 2$ & $-7.80000^{*}$ & $0.006^{*}$ \\
\hline & & $\mathrm{K} 3$ & $-13.90000^{*}$ & $0.000^{*}$ \\
\hline & & K4 & $-13.60000^{*}$ & $0.000 *$ \\
\hline & & K5 & $-20.62000^{*}$ & $0.000^{*}$ \\
\hline & $\mathrm{K} 2$ & K3 & $-6.10000^{*}$ & $0.033^{*}$ \\
\hline & & K4 & $-5.80000^{*}$ & $0.031 *$ \\
\hline & & K5 & $-12.82000^{*}$ & $0.000^{*}$ \\
\hline & K3 & K4 & 0.30000 & 0.911 \\
\hline & & K5 & $-6.72000^{*}$ & $0.020 *$ \\
\hline & K4 & K5 & $-7.02000^{*}$ & $0.011^{*}$ \\
\hline
\end{tabular}

indirectly also showed that the changes in antioxidant enzyme concentrations with aging could not overcome the increased free radical concentrations in the body. At baseline relatively constant MDA concentrations were found, followed by slightly increased MDA concentrations in the group of 32 weeks (K3) and decreased MDA concentrations in the group of 40 weeks (K4). At the age of 48 weeks a two-fold increase in MDA concentrations was found as compared with both the ages of 12 and 24 weeks.

The results of this study showing increased MDA concentrations with aging are apparently similar to the results of the study by Hamezah et al., ${ }^{(19)}$ which showed increased MDA concentrations and decreased glutathione peroxidase (GPx) concentrations in older rats (27 weeks). The linear increase in MDA concentration started in 18- to 27 -week old rats. On the other hand, the GPx concentrations decreased in the same age range, showing that lipid peroxidation increases with aging. This indicates that the preventive measures of the body by means of antioxidants (in this case GPx) was inadequate, as shown by the mutually inverse MDA and GPx concentration graphs. The study by Kim et al. ${ }^{(24)}$ showed that increases in the concentrations of endogenous metabolites (lysophosphatidylcholines/lysoPCs, comprising 1ysoPC16:0, 1ysoPC18:0, 1ysoPC18:2, lysoPC20:4, and lysoPC 20:5, and linoleyl carnitine) lead to increases in inflammation (Creactive protein/CRP and interleukin-6/IL-6), oxidative markers (oxidized low-density lipoprotein/ox-LDL, MDA and 8-epiprostaglandin F2alpha/8-epi-PGF ${ }_{2 \alpha}$ ) and brachial arterial stiffness (brachial-ankle pulse wave velocity/ ba-PWV) in 57-year old men. There was a positive correlation between changes in lysoPC16:0 concentration with changes in the concentrations of 8-epi-PGF ${ }_{2 \alpha}, \mathrm{MDA}, \mathrm{CRP}, \mathrm{IL}-$ 6 and ba-PWV. This suggests that lipid peroxidation, and increased inflammation and vascular stiffness in aging humans is caused by increases in lysoPC16:0.

Aging is also marked by increased body weight, which in this study was observed from the ages of 24 to 48 weeks. This increase was 1-2 times the baseline body weight in group $\mathrm{K} 1$. The increases in body weight in this study are in line with those in the study by Chinedu et al. ${ }^{(20)}$ 
Table 3. LSD post-hoc test on the weight of liver, heart, kidneys and testes

of mice (Mus musculus) in various groups

\begin{tabular}{|c|c|c|c|c|}
\hline \multirow{2}{*}{$\frac{\text { Organ weight }}{\text { Liver }}$} & \multicolumn{2}{|c|}{ Group } & \multirow{2}{*}{$\frac{\text { Mean difference }}{-0.46060}$} & \multirow{2}{*}{$\frac{\text { p value }}{0.075}$} \\
\hline & $\mathrm{K} 1$ & $\mathrm{~K} 2$ & & \\
\hline & & $\mathrm{K} 3$ & -0.48610 & 0.077 \\
\hline & & K4 & $-0.76500^{*}$ & $0.006^{*}$ \\
\hline & & K5 & $-0.84280^{*}$ & $0.003 *$ \\
\hline & $\mathrm{K} 2$ & $\mathrm{~K} 3$ & -0.02550 & 0.923 \\
\hline & & K4 & -0.30440 & 0.229 \\
\hline & & $\mathrm{K} 5$ & -0.38220 & 0.135 \\
\hline & K3 & K4 & -0.27890 & 0.296 \\
\hline & & $\mathrm{K} 5$ & -0.35670 & 0.185 \\
\hline & K4 & $\mathrm{K} 5$ & -0.07780 & 0.754 \\
\hline \multirow[t]{10}{*}{ Heart } & K1 & $\mathrm{K} 2$ & -0.02500 & 0.226 \\
\hline & & $\mathrm{K} 3$ & $-0.06010^{*}$ & $0.011 *$ \\
\hline & & K4 & $-0.06940^{*}$ & $0.003 *$ \\
\hline & & $\mathrm{K} 5$ & $-0.11340^{*}$ & $0.000^{*}$ \\
\hline & $\mathrm{K} 2$ & $\mathrm{~K} 3$ & -0.03510 & 0.114 \\
\hline & & K4 & $-0.04440^{*}$ & $0.039^{*}$ \\
\hline & & K5 & $-0.08840^{*}$ & $0.000 *$ \\
\hline & K3 & K4 & -0.00930 & 0.666 \\
\hline & & K5 & $-0.05330^{*}$ & $0.021 *$ \\
\hline & K4 & $\mathrm{K} 5$ & $-0.04400^{*}$ & $0.040 *$ \\
\hline \multirow[t]{10}{*}{ Kidneys } & K1 & $\mathrm{K} 2$ & -0.11820 & 0.135 \\
\hline & & K3 & $-0.35520^{*}$ & $0.000^{*}$ \\
\hline & & K4 & $-0.21500^{*}$ & $0.010^{*}$ \\
\hline & & K5 & $-0.28180^{*}$ & $0.001 *$ \\
\hline & $\mathrm{K} 2$ & $\mathrm{~K} 3$ & $-0.23700^{*}$ & $0.008 *$ \\
\hline & & K4 & -0.09680 & 0.217 \\
\hline & & $\mathrm{K} 5$ & $-0.16360^{*}$ & $0.044 *$ \\
\hline & K3 & K4 & 0.14020 & 0.097 \\
\hline & & K5 & 0.07340 & 0.372 \\
\hline & K4 & $\mathrm{K} 5$ & -0.06680 & 0.389 \\
\hline \multirow{10}{*}{ Testes } & K1 & $\mathrm{K} 2$ & -0.05340 & 0.060 \\
\hline & & $\mathrm{K} 3$ & $-0.08200^{*}$ & $0.009^{*}$ \\
\hline & & K4 & $-0.13340^{*}$ & $0.000 *$ \\
\hline & & K5 & $-0.12340^{*}$ & $0.000 *$ \\
\hline & $\mathrm{K} 2$ & $\mathrm{~K} 3$ & -0.02860 & 0.325 \\
\hline & & K4 & $-0.08000^{*}$ & 0.007 * \\
\hline & & $\mathrm{K} 5$ & $-0.07000^{*}$ & $0.017^{*}$ \\
\hline & K3 & $\mathrm{K} 4$ & -0.05140 & 0.085 \\
\hline & & K5 & -0.04140 & 0.160 \\
\hline & $\mathrm{K} 4$ & $\mathrm{~K} 5$ & 0.01000 & 0.712 \\
\hline
\end{tabular}

who showed that increases in body weight in humans are clearly found from age 13-19 years up to 40-59 years. In older age groups the rate in weight increase was similar to that of the group of 40-59 years. This shows that after the age of 40-59 years the rate of weight increase showed a static trend. In contrast to the latter study, we did not determine the body weight of mice older than 48 weeks, so that our study was unable to describe the trend observed in mice older than 48 weeks.
Dutta and Sengupta ${ }^{(25)}$ state that based on their respective life spans, 9-day old mice are the homologs of 1- year old humans. Therefore the ages of 12, 24, 32, 40, and 48 weeks in mice of the present study are homologous to the ages of $9,19,25,31$, and 37 years in humans. Accordingly, when converted to human ages, the increase in MDA concentrations in this study will be found around the age of 40 years. This agrees with the free radical theory which states that the defense mechanism against increased 
Table 4. Post-hoc test on weights of brain and spleen relative to body weight of mice (Mus musculus) in various

\begin{tabular}{|c|c|c|c|c|}
\hline Relative organ weight & & & Mean difference & p value \\
\hline \multirow[t]{10}{*}{ Brain } & K1 & $\mathrm{K} 2$ & $0.003469^{*}$ & $0.007 *$ \\
\hline & & $\mathrm{K} 3$ & $0.006096^{*}$ & $0.000 *$ \\
\hline & & $\mathrm{K} 4$ & $0.003901^{*}$ & $0.003 *$ \\
\hline & & K5 & $0.005413^{*}$ & $0.000 *$ \\
\hline & K2 & K3 & $0.002627^{*}$ & $0.045^{*}$ \\
\hline & & K4 & 0.000433 & 0.711 \\
\hline & & K5 & 0.001944 & 0.108 \\
\hline & K3 & K4 & -0.002194 & 0.088 \\
\hline & & K5 & -0.000683 & 0.582 \\
\hline & K4 & K5 & 0.001511 & 0.205 \\
\hline \multirow[t]{10}{*}{ Spleen $\#$} & K1 & $\mathrm{K} 2$ & & 0.05 \\
\hline & & K3 & & 0.05 \\
\hline & & K4 & & 0.35 \\
\hline & & K5 & & 0.12 \\
\hline & K2 & K3 & & 0.46 \\
\hline & & K4 & & $0.01 *$ \\
\hline & & K5 & & $0.01 *$ \\
\hline & K3 & K4 & & $0.01 *$ \\
\hline & & K5 & & $0.01 *$ \\
\hline & K4 & K5 & & 0.25 \\
\hline
\end{tabular}

$\ddagger$ : LSD post hoc test, ${ }^{\star *}$ : Mann Whitney post hoc test

free radicals in the human body will become less effective at the age of 40 years. ${ }^{(7)}$ Apparently this was the cause of the increased MDA concentrations in group $\mathrm{K} 5$ of the present study. The increases in body weight that were found from the age of 24 to 48 weeks in the mice of this study are homologous to the increases in body weight in the study of Chinedu et al., ${ }^{(20)}$ i.e. the age group of 19 to 40 years. These increases in body weight show the increasing development of the body and the increased intake by the body.

This study showed an increase in the weight of the brain with increasing age. The increased brain weight apparently reflects increases in brain ventricular volume in the study of Chen et al. ${ }^{(16)}$ However, in contrast to the study by Chen et al. ${ }^{(16)}$ that showed an increasing trend in ventricular volume particularly at the age of fewer than 20 weeks, in our study the brain weight showed a linear increase with age (increased up to the age of 48 weeks). This is understandable because of the differences in the observed parameters. The parameter of brain weight in the present study was measured by weighing the cerebrum and cerebellum of the mice. Therefore, the increases in brain weight in our study not only reflect increases in brain ventricular volume but also increases in other structures in both cerebral hemispheres as well as in the cerebellum. Similar to the increase in brain ventricular volume, the volume of the cerebellum apparently also increases with age. ${ }^{(19)}$ Apparently both of these caused the increases in brain weight in this study.

The present study showed increases in heart weight with increasing age, with a peak at the age of 48 weeks. The weight increase of the heart apparently depicts hypertrophy of the heart with age, accompanied by increases in extracellular connective tissue formation. The aging process causes a reduction in cardiomyocytes, and the cardiac hypertrophy and increased production of the extracellular matrix with age is a compensatory mechanism to overcome the reduction in cardiomyocytes. ${ }^{(26)}$ 
The results of our study showed increases in organ weight of the kidneys, liver, spleen and testes with increasing age. The increases in the weight of the kidneys, liver, and spleen in our study are in line with those of Caglar et al., ${ }^{(13)} \mathrm{Kim}$ et al. ${ }^{(14)}$ and Melchioretto et al. ${ }^{(18)}$, which are the results of autopsies on humans. The increases in the weight of the kidneys, liver, and spleen occurred concomitantly with increases in individual body weight and body mass index (BMI). ${ }^{(13,14,18)}$ The spleen is subject to growth up to the age of 25 years in humans. ${ }^{(13)}$ In line with abovementioned studies, the increased weight of the spleen in our study could be observed starting from the age of 40 weeks. The increase in the volume of the kidneys in older rats was apparently also marked by a decrease in renal function. ${ }^{(18)}$ In contrast to the study results of Melchioretto et al. ${ }^{(18)}$ who state that increases in the volume of the kidneys are observable in rats from the age of 12 months, our study showed a peak increase in the weight of the kidneys occurring at the ages of 8 months ( 32 weeks) and 12 months (48 weeks). This may be due to the differences in experimental animals used. However, our study results are in line with those of Kim et al. ${ }^{(14)}$ who state that increases in the weight of the kidneys and liver in humans can be found in middle age. In line with the latter study, the increase in weight of both organs was found at the age of 48 weeks (homologous with 37 years in humans). This is apparently associated with the function of both organs that play a role in metabolic degradation.

The present study also showed that aging does not cause statistically significant changes in the weight of the thymus. The peak increase in the weight of the thymus occurs at the age of 40 weeks. The decreases in the weight of the thymus in mice at the age of 48 weeks may have possibly occurred as a result of involution. This is supported by the increased activity of $\beta$ galactosidase in mice at the ages of 12 up to 18 months, this enzyme being one of the markers of aging. At these ages also there are increased markers of DNA damage and failure of cell replication. ${ }^{(17)}$
The present study showed that the increases in organ weight occurred at different points in time. The peak increases in the weight of the kidneys occurred at age 32 weeks whereas increases in the weight of the liver, heart, testes, brain and spleen occurred at age 48 weeks. This showed that only macroscopic changes occur in the majority of murine organs at age 48 weeks (homologous to age 37 years in humans).

Additionally, the present study aimed to determine the relative organ weight changes with increasing age. The relative organ weight is the ratio of organ weight to body weight. This study showed that there was a relative decrease in brain weight with increasing age. This was apparently due to atrophy of the gyri and widening of the sulci and cerebral ventricles. ${ }^{(14)}$ In contrast to the study results on the weight of individual organs that showed increased brain weight with increasing age, there was a decreasing trend of the brain-to-body weight ratio. This showed that aging causes a far greater increase in body weight in comparison with the weight increase of the brain itself. ROS induce vascular injury and organ dysfunction. ${ }^{(28)}$ Increased ROS concentration is frequently associated with decreased elasticity, constriction, and relaxation of the blood vessels. Aging causes increases in ROS concentration that induce lipid peroxidation, resulting in cell membrane damage and ultimately dysfunction of cell-surface receptors and enzymes. Increases in MDA concentrations from lipid peroxidation will inactivate cellular proteins. ${ }^{(7)}$

One study showed weight increase and hypertrophy of white adipose tissue (WAT) with age in the internal organs and subcutaneous tissues. ${ }^{(29)}$ Secretion of the pro-inflammatory cytokines TNF- $\alpha$ and IL- 6 by adipocytes and accumulation of macrophages in adipose tissue causes a chronic systemic inflammatory condition (inflammaging), ${ }^{(30)}$ resulting in DNA damage and degeneration in various body tissues. Other studies showed that aging increases foci of DNA damage in various organs, such as the lungs, liver, and spleen. Ultimately failure of DNA repair causes apoptosis of the cells. ${ }^{(10,31)}$ 
Aging is also marked by the occurrence of disorders of metabolism. Decreases in growth hormone $(\mathrm{GH})$, and insulin growth factor-1 (IGF-1) and increases in insulin resistance are recognized as the main markers for age-related disorders of metabolism. ${ }^{(30)}$ IGF-1 induces increased production of collagens and various other components of the extracellular matrix (ECM). ${ }^{(32)}$ In the kidneys, chronic disorders of cellular metabolism decrease the expression of sirtuin-1 (SIRT-1) that plays an important role in cell survival. The decreased SIRT-1 expression results in decreases in the function of blood vessels and also in the production of matrix metalloproteinase-14 (MMP-14), ${ }^{(33)}$ both of which cause tissue fibrosis. ${ }^{(10,33)}$ It is apparently these conditions that underlie the age-related changes in organ weight.

The investigators are aware of the numerous limitations of this study. First, this study used small number of data on aging in the experimental animals and the small number of study subjects in each group. The investigators also selected the parameter of body weight without using the parameter of body mass index (BMI) as one of the variables under study. Further studies should be conducted to know the patterns of morphological changes, both anatomical and histological, which occur during the lifetime of an individual. It is hoped that with the knowledge of the pattern of changes that occur with age in experimental animals, will come the knowledge of the pattern of changes in free radicals and in the weight of internal organs in humans. By knowing these patterns of changes, age-related standard normal values will be obtained for each internal organ and free radical in experimental animals in general and in humans in particular.

\section{CONCLUSION}

There were significant age-related changes in serum MDA, body weight, and the weights of the liver, heart, kidneys, testes, brain and spleen. The peak increase in the weights of the kidneys and thymus occurred earlier than that of the changes in MDA concentration, body weight and the weights of several organs (liver, heart, testes, brain and spleen). The rate of increase of the weights of the brain and spleen was greater than that of the body weight.

\section{ACKNOWLEDGMENT}

The authors wish to thank the technicians of the Physiology Laboratory, Faculty of Medicine, UII, who assisted in the course of this study.

\section{CONFLICT Of INTEREST}

The investigators declare that there is no conflict of interest from the start of this study up to and including the writing up of the manuscript. This study was self-funded by the investigators.

\section{CONTRIBUTORS}

DNA and IF contributed fully to the study design, data collection, writing and revision of the manuscript. Both authors read and approved the revised manuscript.

\section{REFERENCES}

1. Niccoli T, Partridge L. Ageing as a risk factor for disease. Curr Biol 2012;11:R741-52. doi: 10.1016/ j.cub.2012.07.024.

2. Thakur RP, Banerjee A, Nikumb VB. Health problems among the elderly: a cross-sectional study. Ann Med Health Sci Res 2013;3:19-25. doi: 10.4103/2141-9248.109466.

3. Reji RK, Kaur S. Prevalence of common physical health problems among elderly in selected old age homes of a cosmopolitan city. IJSR 2015;4: 1034-8.

4. Tiwari SC, Trichal M, Mehrotra B, et al. A study of awareness of health problems of the elderly with reference to mental health. Delhi Psychiatry J 2009;12:263-8.

5. Birben E, Sahiner UM, Sackesen C, et al. Oxidative stress and antioxidant defense. WAO J 2012;5:9 19. doi:10.1097/WOX.0b013e3182439613. 
6. Sharma S, Singh R, Kaur M, et al. Late-onset dietary restriction compensates for age-related increase in oxidative stress and alterations of HSP 70 and synapsin 1 protein levels in male Wistar rats. Biogerontology 2010;11:197-209. doi: 10.1007/s10522-009-9240-4.

7. Całyniuk B, Grochowska-Niedworok E, Walkiewicz KW, et al. Malondialdehyde (MDA) - product of lipid peroxidation as marker of homeostasis disorders and aging. Ann Acad Med Siles 2016;70:224-8. doi:10.18794/aams/65697.

8. Marseglia L, Manti S, D’Angelo G, et al. Oxidative stress in obesity: a critical component in human diseases. Int J Mol Sci 2015;16:378-400. doi: 10.3390/ijms16010378.

9. Mittal PC, Kant R. Correlation of increased oxidative stress to body weight in disease-free post menopausal women. Clin Biochem 2009;42:1007-11. doi: 10.1016/j.clinbiochem.2009. 03.019 .

10. Sanada F, Taniyama Y, Muratsu J, et al. Source of chronic inflammation in aging. Front Cardiovasc Med 2018; 5:12. doi: 10.3389/fcvm.2018.00012.

11. Piao Y, Liu Y, Xie X. Change trends of organ weight: background data in Sprague Dawley rats at different ages. J Toxicol Pathol 2013;26: 29-34.

12. Galvan D, Di Pietro PF, Vieira FGK, et al. Increased body weight and blood oxidative stress in breast cancer patients after adjuvant chemotherapy. Breast J 2013;19:555-7.

13. Caglar V, Kumral B, Uygur R, et al. Study of volume, weight and size of normal pancreas, spleen and kidney in adults autopsies. Forensic MedAnat Res 2014;2:63-9. doi : 10.4236/fmar.2014. 23012.

14. Kim YS, Kim DI, Cho SY, et al.. Statistical analysis for organ weights in Korean adult autopsies. Korean J Anat 2009:42:219-24.

15. Deepika K, Sushma M, Kumar V. Study of the weights of human heart and liver in relation with age, gender and body height. IJRMS 2017;5:346973. doi:10.18203/2320-6012.ijrms20173543.

16. Chen CV, Tung Y, Changa C. A lifespan MRI evaluation of ventricular enlargement in normal aging mice. Neurobiol Aging 2011;32:2299-307. doi: 10.1016/j.neurobiolaging.2010.01.013.

17. Aw D, Silva AB, Maddick M, et al. Architectural changes in the thymus of aging mice. Aging Cell 2008;7:158-67. doi: 10.1111/j.1474-9726.2007. 00365.x.

18. Melchioretto EF, Zeni M, da Luz Veronez DA, et al. Quantitative analysis of the renal aging in rats. Stereological study. Acta Cir Bras 2016;31:34652. doi: http://dx.doi.org/10.1590/S0102865020160050000009 .
19. Hamezah HS, Durani LW, Ibrahim NF, et al. Volumetric changes in the aging rat brain and its impact on cognitive and locomotor functions. Exp Gerontol 2017;99:69-79. doi: 10.1016/j.exger. 2017. 09.00.

20. Chinedu SN, Emiloju OC, Azuh DE, et al. Association between age, gender and body weight in educational institutions in Ota, Southwest Nigeria. Asian J Epidemiol 2017;10: 144-9. doi: 10.3923/aje.2017.144.149.

21. Luceri C, Bigagli E, Femia AP, et al. Aging related changes in circulating reactive oxygen species (ROS) and protein carbonyls are indicative of liver oxidative injury. Toxicol Reports 2018;141-5. https://doi.org/10.1016/j.toxrep.2017.12.017.

22. Gomes P, Simão S, Silva E, et al. Aging increases oxidative stress and renal expression of oxidant and antioxidant enzymes that are associated with an increased trend in systolic blood pressure. Oxid Med Cell Longev 2009;2:138-45

23. Charan J, Kantharia ND. How to calculate sample size in animal studies? J Pharmacol Pharmacother 2013;4:303-6.

24. Kim JY, Kim OY, Paik JK, et al. Association of agerelated changes in circulating intermediary lipid metabolites, inflammatory and oxidative stress markers, and arterial stiffness in middle-aged men. Age 2013;35:1507-19. doi: 10.1007/s11357-0129454-2.

25. Dutta S, Sengupta P. Men and mice: relating their ages. Life Sci 2016;152: 244-8. doi: 10.1016/j.lfs. 2015.10.025.

26. Bernhard D, Laufer $\mathrm{G}$. The aging cardiomyocyte: a mini-review. Gerontology 2008;54:24-31. doi: 10.1159/000113503.

27. Kogawa T, Kashiwakura I. Relationship between obesity and serum reactive oxygen metabolites in adolescents. Environ Health Prev Med 2013;18: 451-7. doi: 10.1007/s12199-013-0341-y.

28. Gonçalves LD, Machado TQ, Castro-Pinheiro C, et al. Ageing is associated with brown adipose tissue remodelling and loss of white fat browning in female C57BL/6 mice. Int J Exp Path 2017;98: 100-08. doi: 10.1111/iep.12228.

29. Masternak MM, Bartke A. Growth hormone, inflammation and aging. Pathobiol Aging Age Rel Dis 2012; 2:1, 17293. doi: 10.3402/ pba.v2i0.17293.

30. Marques EB, de Magalhães Barros RB, de Novaes Rocha N, et al. Aging and cardiac, biochemical, molecular and functional changes: an experimental study. Int J Cardiovasc Sci 2015;28: 42-50. http://www.dx.doi.org/10.5935/2359-4802. 20150007.

31. Freitas-Rodrígueza S, Folguerasa AR, LópezOtína C. The role of matrix metalloproteinases in 
aging: tissue remodeling and beyond. BBA Mol Cell Res 2017;1864:2015-25. http://dx.doi.org/ 10.1016/j.bbamcr.2017.05.007.

32. Vasko R, Xavier S, Chen J, et al. Endothelial sirtuin 1 deficiency perpetrates nephrosclerosis through down regulation of matrix metalloproteinase-14: relevance to fibrosis of vascular senescence. J Am Soc Nephrol 2014;25:276-91. doi: 10.1681/ ASN.2013010069.
33. Horn MA, Trafford AW. Aging and the cardiac collagen matrix: novel mediators of fibrotic remodelling. J Mol Cell Cardiol 2016;93:175-85. http://dx.doi.org/10.1016/j.yjmcc.2015.11.005. 